\title{
Effects of buthionine sulfoximine nifurtimox and benznidazole upon trypanothione and metallothionein proteins in Trypanosoma cruzi.
}

\author{
JUAN DIEGO MAYA ${ }^{1 *}$, ANDRÉS RODRÍGUEZ ${ }^{1}$, LAURA PINO$^{1}$, ADRIANA PABÓN $^{2}$, \\ JORGE FERREIRA $^{1}$, MARIO PAVANI ${ }^{1}$, YOLANDA REPETTO ${ }^{1}$ and ANTONIO MORELLO ${ }^{1}$
}

\author{
${ }^{1}$ Faculty of Medicine, ICBM, Program of Molecular and Clinical Pharmacology University of Chile, Casilla \\ 70000, Santiago 7, Chile. \\ ${ }^{2}$ Faculty of Medicine, Malaria Group, University of Antioquia, Cra 51D \#62-29, Medellín, Colombia.
}

\begin{abstract}
Proteins rich in sulfhydryl groups, such as metallothionein, are present in several strains of the parasite Trypanosoma cruzi, the etiological agent of Chagas' disease. Metallothionein-like protein concentrations ranged from 5.1 to $13.2 \mathrm{pmol} / \mathrm{mg}$ protein depending on the parasite strain and growth phase. Nifurtimox and benznidazole, used in the treatment of Chagas' disease, decreased metallothionein activity by approximately $70 \%$. T. cruzi metallothionein was induced by $\mathrm{ZnCl}_{2}$. Metallothionein from $T$. cruzi was partially purified and its monobromobimane derivative showed a molecular weight of approximately 10,000 Da by SDS-PAGE analysis. The concentration of trypanothione, the major glutathione conjugate in $T$. cruzi, ranged from 3.8 to $10.8 \mathrm{nmol} / \mathrm{mg}$ protein, depending on the culture phase. The addition of buthionine sulfoximine to the protozoal culture considerably reduced the concentration of trypanothione and had no effect upon the metallothionein concentration. The possible contribution of metallothionein-like proteins to drug resistance in T. cruzi is discussed.
\end{abstract}

Key terms: Trypanosoma cruzi, metallothionein, glutathione, trypanothione, benznidazole, nifurtimox, buthionine sulfoximine.

\section{INTRODUCTION}

Several thiol-containing molecules play an important role in trypanosomatid defense against free radicals and electrophilic agents. The most important thiol molecules are trypanothione (bis-glutathionyl spermidine, $\left.\mathrm{T}(\mathrm{SH})_{2}\right)$, glutathione $(\mathrm{GSH})$, ovothiols (Fairlamb and Cerami, 1985; Steenkamp and Spies, 1994; Repetto et al., 1996; Maya et al., 1997; Maya et al., 1999; Maya et al., 2001a; Ariyanayagam and Fairlamb, 2001; Steenkamp, 2002), and metallothionein-like proteins (MTs), as shown in this paper. All these compounds act as free radical scavengers by virtue of their thiol groups.
Metallothioneins (MTs) are low molecular weight, soluble proteins found in vertebrates, invertebrates and microorganisms. In addition, MTs have a high content of cysteinyl residues; in this respect, they are very similar to $\mathrm{T}(\mathrm{SH})_{2}$. MTs appear to be mainly cytoplasmic but several studies have shown that these proteins are also present in nuclei (Jeremias and Kägi, 1991; Sato and Bremner, 1993). The term metallothionein may be applied to proteins with the following properties: a) low molecular weight (6-14 kDa); b) high content of heavy metals (6-12 metal atoms per molecule); c) amino acid composition containing approximately one third of cysteinyl residues and without disulfide

Corresponding author: Prof. Dr. Juan Diego Maya. University of Chile, Faculty of Medicine, Molecular and Clinical Pharmacology Program. Casilla 70086, Santiago 7, Chile. Telephone: (56 2) 678-6071 - Fax: (56 2) 735-5580.

E-mail: jmaya@med.uchile.cl 
bonds, and no aromatic amino acids or histidine; d) amino acid sequence with conserved distribution of cysteinyl residues; e) single polypeptide chain; f) heat stability; and g) the presence of isoforms (Sato and Bremner, 1993).

MT has multiple functions that include the detoxification of drugs and heavy metals, the hepatic metabolism of zinc and copper, and the scavenging of electrophilic compounds and free radicals (Lazo et al., 1998; Klaassen et al., 1999; Hanada, 1998; He et al., 2000: Coyle et al., 2002; Sato and Kondoh, 2002). Many agents producing oxidative or physical stress induce these proteins. Hepatic MT content may be increased 20-30 fold by several chemical agents, such as heavy metals (Dunn et al., 1987; Jeremias and Kägi, 1991; Sato and Bremner, 1993).

Nifurtimox and benznidazole are nitroheterocyclic compounds used as anti- $T$. cruzi drugs in the treatment of Chagas' disease (Sanchez et al., 2002; Contreras et al., 2002). The susceptibility of several $T$. cruzi strains and forms to nifurtimox and benznidazole correlate negatively with the intracellular free thiol $\left(\mathrm{GSH}\right.$ and $\left.\mathrm{T}(\mathrm{SH})_{2}\right)$ levels (Maya et al., 1997; Maya et al., 2001a). Buthionine sulfoximine (BSO), an inhibitor of glutathione (GSH) synthesis, renders Trypanosoma cruzi parasites more susceptible to nifurtimox and benznidazole (Moncada et al., 1989; Repetto et al., 1996; Maya et al., 1997). The significant decrease in the GSH and $\mathrm{T}(\mathrm{SH})_{2}$ concentration caused by conjugation with nifurtimox and benznidazole nitroreductive metabolites could explain the toxic effects of both drugs (Maya et al., 1997). Because of their high content of cysteinyl residues, MTs may play a similar or complementary role to $\mathrm{GSH}$ and $\mathrm{T}(\mathrm{SH})_{2}$ in detoxification and drug metabolism in $T$. cruzi parasites.

MTs have been isolated from many sources including protozoa such as Oxytrichia and Tetrahymena (Piccini et al., 1994; Irato et al., 1995). However, in this paper we describe for the first time evidence of the presence of an MT-like protein in a protozoon of medical importance and its possible role in its resistance to drugs.

\section{MATERIALS AND METHODS}

\section{Parasites}

T. cruzi epimastigotes (Tulahuén, LQ and MF strains and CL-Brener and Dm28c clones) were grown at $28^{\circ} \mathrm{C}$ in modified Diamond's medium as described previously (Maya et al., 1997). $80 \times 10^{6}$ parasites are equivalent to 1 $\mathrm{mg}$ of protein or $12 \mathrm{mg}$ of wet weight.

\section{Metallothionein analysis}

MT concentration was determined by the radioactive cadmium method (Eaton and Toal, 1982). Basically, the parasites were suspended in an antioxidant and antiproteolytic cocktail (1 mM phenyl methyl sulfonyl fluoride (PMSF), $0.1 \mathrm{mM} \mathrm{N} \alpha-\mathrm{p}$ Tosyl-L-lysine chloro methyl ketone hydrochloride (TLCK), $0.05 \mathrm{mM}$ transepoxysuccinyl L-leucylamido (4-guanidino)butane (E64), $2 \mathrm{mM}$ orthophenanthroline, 5 $\mathrm{mM}$ mercaptoethanol, Tris- $\mathrm{HCl} 10 \mathrm{mM}, \mathrm{pH}$ $7,4)$, sonicated twice for 30 seconds, and heated for two minutes at $100^{\circ} \mathrm{C}$. The sample was centrifuged at $10,000 \mathrm{x} \mathrm{g}$ for 5 minutes. An aliquot of $200 \mu \mathrm{L}$ of the supernatant was mixed with $100 \mu \mathrm{L}$ of a Tris- $\mathrm{HCl} 10 \mathrm{mM}, \mathrm{pH}$ $7.4{ }^{109} \mathrm{CdCl}_{2}$ solution containing $2 \mu \mathrm{g}$ of $\mathrm{CdCl}_{2}$ per $\mathrm{mL}$ and one $\mu \mathrm{Ci}$ per $\mathrm{mL}$. The mix was incubated for ten minutes at room temperature. Then, $100 \mu \mathrm{L}$ of fresh solution of $2 \%$ bovine hemoglobin was added and heated for 2 minutes at $100^{\circ} \mathrm{C}$ followed by centrifugation at $10,000 \mathrm{x} \mathrm{g}$ for 10 minutes. The supernatant was treated twice with hemoglobin. Finally the resultant supernatant was counted in a gamma counter. The parasite's GSH and $\mathrm{T}(\mathrm{SH})_{2}$ and mercaptoethanol did not interfere with the MT determination. The concentration of MT was calculated assuming that six atoms of cadmium bind to a molecule of MT (Eaton and Toal, 1982), thus one picomole of MT corresponds to approximately $1080 \mathrm{cpm}$.

\section{Analysis of thiols}

Reduced GSH, glutathionyl-spermidine and $\mathrm{T}(\mathrm{SH})_{2}$ in control and drug-treated parasites 
were determined by derivatization with monobromobimane (Thiolyte) and then separated by HPLC as described previously (Fairlamb et al., 1987; Repetto et al., 1996).

\section{Effect of nifurtimox and benznidazole upon MT concentration}

On the second day of the exponential growth phase, $400 \times 10^{6}$ parasites $/ \mathrm{ml}$ of the Tulahuén strain were incubated at $28^{\circ} \mathrm{C}$ for 2 hours with nifurtimox and benznidazole, at $2.6 \mathrm{mM}$ final concentration. The control without drugs also was incubated at $28^{\circ} \mathrm{C}$ for two hours. The nifurtimox and benznidazole growth inhibition $\mathrm{IC}_{50}$ is approximately $10 \mu \mathrm{M}$ for $3 \times 10^{6}$ parasites/ $\mathrm{ml}$ (Maya et al., 2003). The concentrations employed correspond to twice the $\mathrm{IC}_{50}$ multiplied by a factor of 260 to correct for the difference in parasite concentration. No lysis of the parasites was observed at these concentrations. MT concentration was determined as described above.

\section{Chromatography of T. cruzi MTs}

Approximately 20 grams wet weight of Dm28c clone epimastigotes were suspended in the antioxidant and antiproteolytic cocktail, sonicated, and centrifuged at $100,000 \mathrm{x} \mathrm{g}$ for 1 hour. The supernatant was heated for 2 minutes at $100^{\circ} \mathrm{C}$. The pellet was discharged, the resulting supernatant was eluted through a Sephadex G-75 column $(1.5 \times 25 \mathrm{~cm})$ with Tris- $\mathrm{HCl}$ $0.1 \mathrm{M}, \mathrm{pH} \mathrm{7.4}$, and one $\mathrm{mL}$ fractions were collected. The MTs were determined by the radioactive cadmium method. Tubes with positive radioactivity were pooled and concentrated by freeze-drying and then suspended in the antiproteolytic and antioxidant buffer and divided in two aliquots. One aliquot was derivatized with monobromobimane (Thiolyte $\left.{ }^{\circledR}\right)$ producing a fluorescent derivative due to the high concentration of thiol groups in MTs (Kosower et al., 1983). The other aliquot was used as such. Both aliquots were eluted through a Sephadex G-75 column (1.5 x 40 $\mathrm{cm})$ with Tris- $\mathrm{HCl} 0.1 \mathrm{M}, \mathrm{pH} 7.4$ buffer.
One $\mathrm{ml}$ fractions were collected, and fluorescence at $385 \mathrm{~nm}$ excitation and 480 emission (RF-540 Spectrofluorophotometer, Shimadzu) or radioactivity in a gamma counter was measured.

\section{SDS-Polyacrilamide Gel Electrophoresis of $M T s$}

Control and MT samples from epimastigotes treated with nifurtimox and benznidazole as described in section 2.4 were derivatized with monobromobimane. Then the parasites were subjected to MT derivatization with monobromobimane as described in section 2.5. The supernatants were dyalized overnight against distilled water, concentrated by lyophilization and separated by $15 \%$ SDS-PAGE. The fluorescent bands corresponding to MT were visualized by UV-transillumination. Monobromobimane-derivatized horse kidney MT standard and prestained molecular weight standards (SigmaMarkerTM Low range [M.W. 650066000]) were used.

\section{Chemicals}

${ }^{109} \mathrm{CdCl}_{2}$ was obtained from NEN Life Science products, Boston, Massachusetts; tryptose, tryptone, yeast extract and fetal calf serum were obtained from Difco, Co.; dimethylsulfoxide was obtained from Merck, Co.; monobromobimane (Thiolyte ${ }^{\circledR}$ ) was obtained from Calbiochem Corp. Horse kidney MT, TLCK, PMFS, and all other chemicals were obtained from Sigma Chemical Co.

\section{Statistical Analysis}

Student's T, ANOVA and Tuckey's or Dunnett's multiple comparison tests were performed when necessary using Prism GraphPad 2.01 software from GraphPad Software Inc.

Values are expressed as mean \pm SD for three independent experiments, each one performed in triplicate. 


\section{RESULTS}

Metallothionein concentration in several strains of Trypanosoma cruzi epimastigotes

Table I shows the concentrations of MTs in several strains of $T$. cruzi. The LQ strain and the clone Dm28c show the highest concentration at the fourth day of growth, equivalent to the exponential phase. In all strains studied, except the CL-Brener clone, the MT content tends to decline in the stationary phase of growth.

The differences between the exponential and stationary phase are significant $(\mathrm{p}<$ 0.0001) except for the CL-Brener clone. No significant differences between clones or strains, except for the Dm28c clone $(p=0.0006)$, were observed.

Effect of buthionine sulfoximine upon total thiol content of Trypanosoma cruzi epimastigotes

Figure 1 shows the change in thiols concentration with culture time. The concentration increased up to $10.8 \mathrm{nmol} / \mathrm{mg}$ protein during the exponential phase of growth, to decline to $3.8 \mathrm{nmol} / \mathrm{mg}$ protein during the stationary phase. These results agree with those reported recently by Ariyanayagam and Fairlamb (2001). Figure 1 also shows that buthionine sulfoximine (BSO) decreased thiols concentration to less than $1 \mathrm{nmol} / \mathrm{mg}$ protein after three days without affecting parasite growth. The main burden of the thiols decrease corresponded to $\mathrm{T}(\mathrm{SH})_{2}$ (data not shown). No effect of BSO upon MT concentration was observed (Table II).

Effect of nifurtimox, benznidazole and zinc chloride upon metallothionein content in Trypanosoma cruzi

Table II shows the effect of nifurtimox and benznidazole upon MT concentration in the Tulahuén epimastigotes. MT content diminished significantly by $73 \%$ in relation to controls with both drugs $(\mathrm{p}<0.001)$. Because of the presence of mercaptoethanol, no oxidized MTs were present and, accordingly, the decrease in the amount of MTs is most probably due to conjugation of the protein with nifurtimox or benznidazole nitro reduced metabolites,

TABLE I

Metallothionein concentration in several strains of Trypanosoma cruzi epimastigotes

\begin{tabular}{lcr}
\hline Strain & \multicolumn{2}{c}{ Growth phase } \\
\hline & Exponential & Stationary \\
\cline { 2 - 3 } & $\mathrm{MTs}^{\mathrm{a}}(\mathrm{pmol} / \mathrm{mg}$ protein $)$ & $7.5 \pm 0.3$ \\
\cline { 2 - 3 } CL-Brener Clone & $7.2 \pm 1.8$ & $6.9 \pm 0.7$ \\
Dm28c Clone & $18.0 \pm 1.8$ & $6.3 \pm 0.9$ \\
LQ & $13.2 \pm 1.3$ & $5.4 \pm 0.6$ \\
MF & $10.2 \pm 1.6$ & $6.3 \pm 0.5$ \\
Tulahuén & $10.0 \pm 1.7$ & 6.5 \\
\hline
\end{tabular}

T. cruzi epimastigotes were grown at $28^{\circ} \mathrm{C}$ in a modified Diamond's medium and harvested on the fourth day of culture (exponential phase) or on the eighth day (stationary phase).

a Metallothioneins (MTs) were determined by the radioactive cadmium method. See Materials and Methods section. 


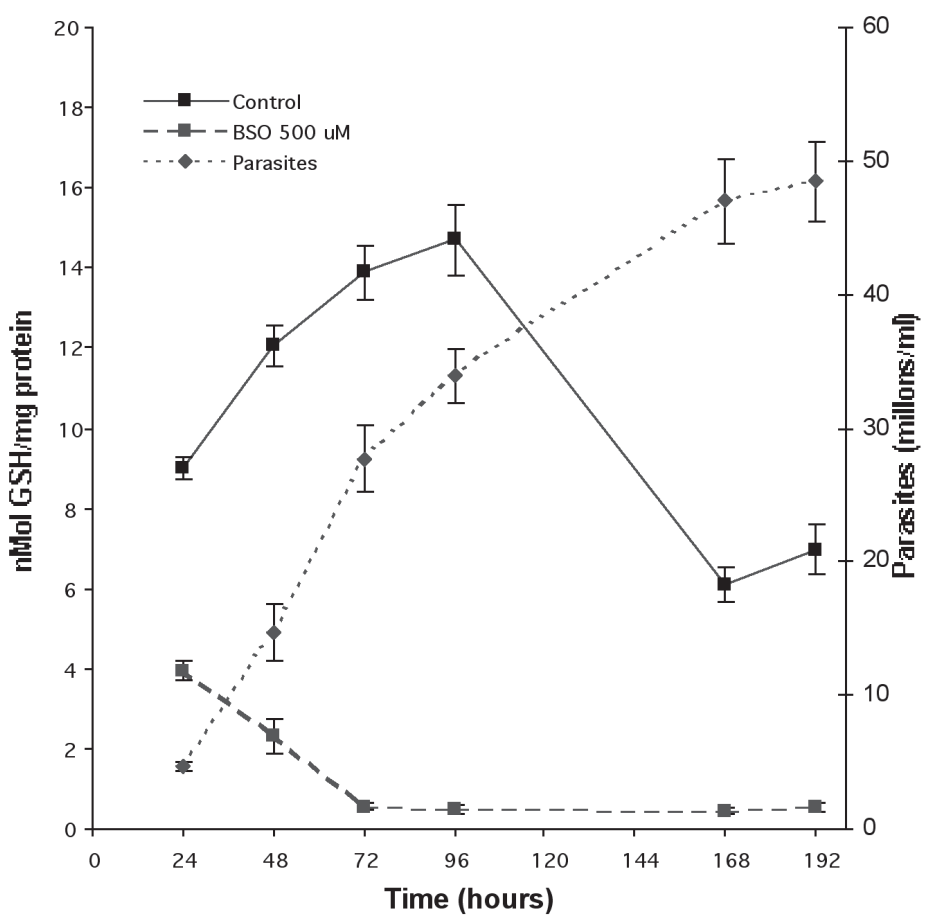

Figure 1. Effect of buthionine sulfoximine upon total thiol content of Trypanosoma cruzi epimastigotes. Continuous line: control thiol content. Hatched line: BSO $0.5 \mathrm{mM}$ added at 0 hours. Total Thiols correspond to the sum of $\mathrm{GSH}, \mathrm{T}(\mathrm{SH})_{2}$ and the intermediate glutathionyl-spermidine and are expressed as GSH. Dotted line: number of parasites treated with BSO $0.5 \mathrm{mM}$. The T. cruzi MF strain was used in these experiments. See Materials and Methods section.

TABLE II

Effect of nifurtimox, benznidazole and zinc chloride upon metallothionein content in Trypanosoma cruzi

\begin{tabular}{lrr}
\hline Treatment & $\begin{array}{c}\text { Metallothionein content } \\
\text { \% of control }\end{array}$ \\
\hline Control & 100.0 & \\
Nifurtimox & 26.3 & \pm 8.0 \\
Benznidazole & 27.5 & \pm 12.8 \\
ZnCl $_{2}$ & 140.0 & \pm 10.0 \\
Buthionine sulfoximine & 100.0 & \\
\hline
\end{tabular}

T. cruzi epimastigotes of the Tulahuén strain were treated with nifurtimox and benznidazole at $2.6 \mathrm{mM}$ concentration, respectively, for two hours and then determined as described in the Materials and Methods section. $\mathrm{ZnCl}_{2} 0.4 \mathrm{mM}$ or buthionine sulfoximine 0.5 $\mathrm{mM}$ was added, and after 24 or 48 hours, respectively, the content of MT was determined. The MT content was determined by the radioactive cadmium method as described in the Materials and Methods section. which react with free thiol groups (Repetto et al., 1996; Maya et al., 1997). MTs cannot bind cadmium or other metals when their thiol groups are oxidized or conjugated with reactive electrophiles.

Table II also shows that $\mathrm{ZnCl}_{2}$ increased the MT concentration by 40 percent.

\section{Chromatographic analysis of metallothioneins of Trypanosoma cruzi}

Figure 2 shows the elution pattern of $T$. cruzi MTs. Monobromobimane derivatized MT from $T$. cruzi eluted in a bimodal pattern at fractions 52-66 and 64-74. Similarly, the native MT detected with the ${ }^{109} \mathrm{Cd}$ method also showed a bimodal pattern. Standard monobromobimanederivatized MT from horse kidney eluted with one peak at 50-58 fractions. Both peaks of native MT showed no measurable 


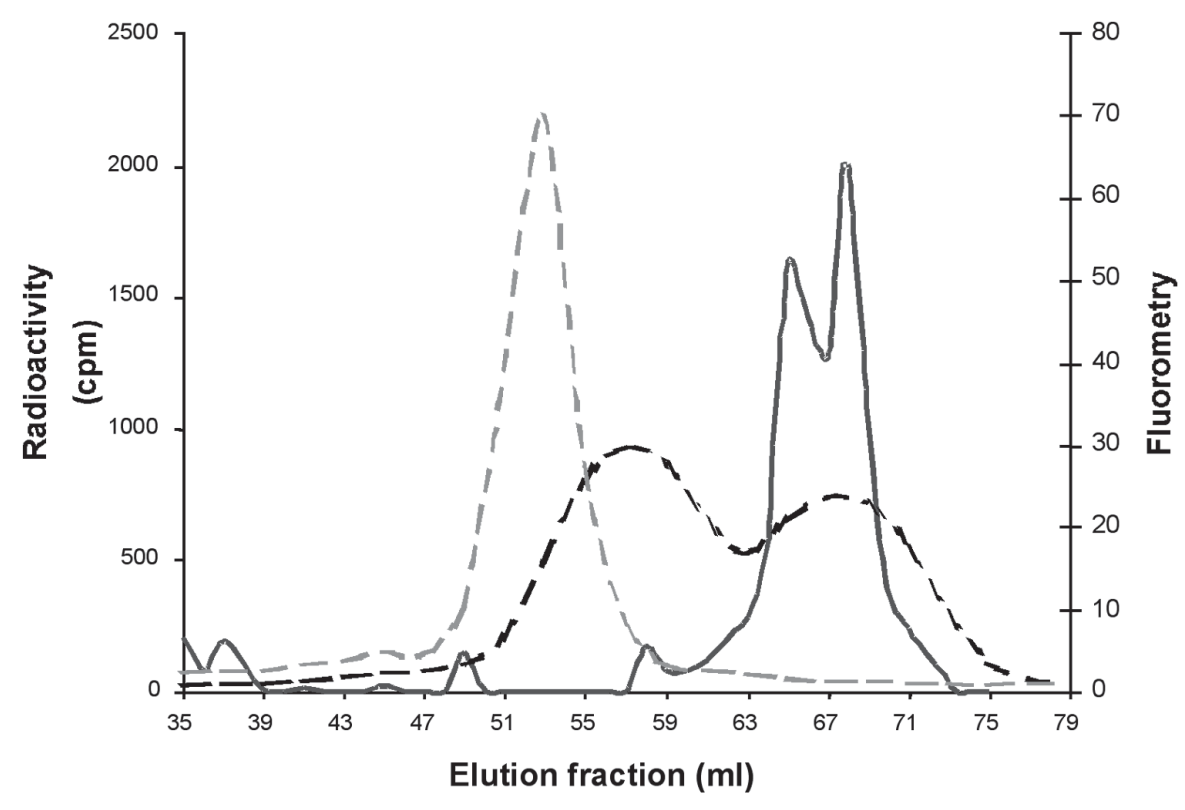

Figure 2. Chromatographic analysis of Metallothioneins of Trypanosoma cruzi. The black continuous line represents the elution pattern of $T$. cruzi MT as assayed by the radioactive cadmium method. The black discontinuous line represents monobromobimane-derivatized T. cruzi MT. The gray discontinuous line represents monobromobimane-derivatized horse kidney standard MT. The T. cruzi Dm28c clone was used in these experiments. See Materials and Methods section for details.

absorbance at $280 \mathrm{~nm}$ and negligible reaction in the Lowry protein determination indicating a low concentration or absence of aromatic amino acids.

When $T$. cruzi homogenates or the fractions obtained from the Sephadex columns (Fig. 2) were prepared without mercaptoethanol, the amount of MTs analyzed by the radioactive cadmium method decreased to almost zero. The addition of mercaptoethanol recovered the original value for MTs, due to the reduction of disulfide bonds formed. Figure 2 also shows the peak obtained from standard horse kidney MT (6800 KDa, Kojima et al., 1976) derivatized with monobromobimane. This standard demonstrates that $T$. cruzi MTs are in the molecular weight range for MTs.

The proteolytic degradation of MT during the homogenization process is inhibited by the addition of antiproteases, excluding this possibility as an explanation for the two peaks observed in Figure 2 when determined by the radioactive cadmium method or by monobromobimane derivatization.

Effect of nifurtimox and benznidazole upon MT-like proteins of Trypanosoma cruzi epimastigotes

Figure 3 shows the 15\% SDS-PAGE of nifurtimox- and benznidazole-treated epimastigotes. Both panels, $\mathrm{A}$ and B, correspond to the same gel. Panel A was stained with Coomasie blue, and Panel B depicts UV-transillumination visualization. Line 1 is the underivatized, standard horse kidney metallothionein. Line 2 is the same standard but monobromobimanederivatized. Lines 3 and 4 correspond to 1.3 $\mathrm{mM}$ and $2.6 \mathrm{mM}$ benznidazole treatment, respectively, and lines 5 and 6 correspond to 1.3 and $2.6 \mathrm{mM}$ nifurtimox treatments, respectively (Table II). Line 7 is the $T$. cruzi monobromobimane control. There are no apparent differences between control 
A

B

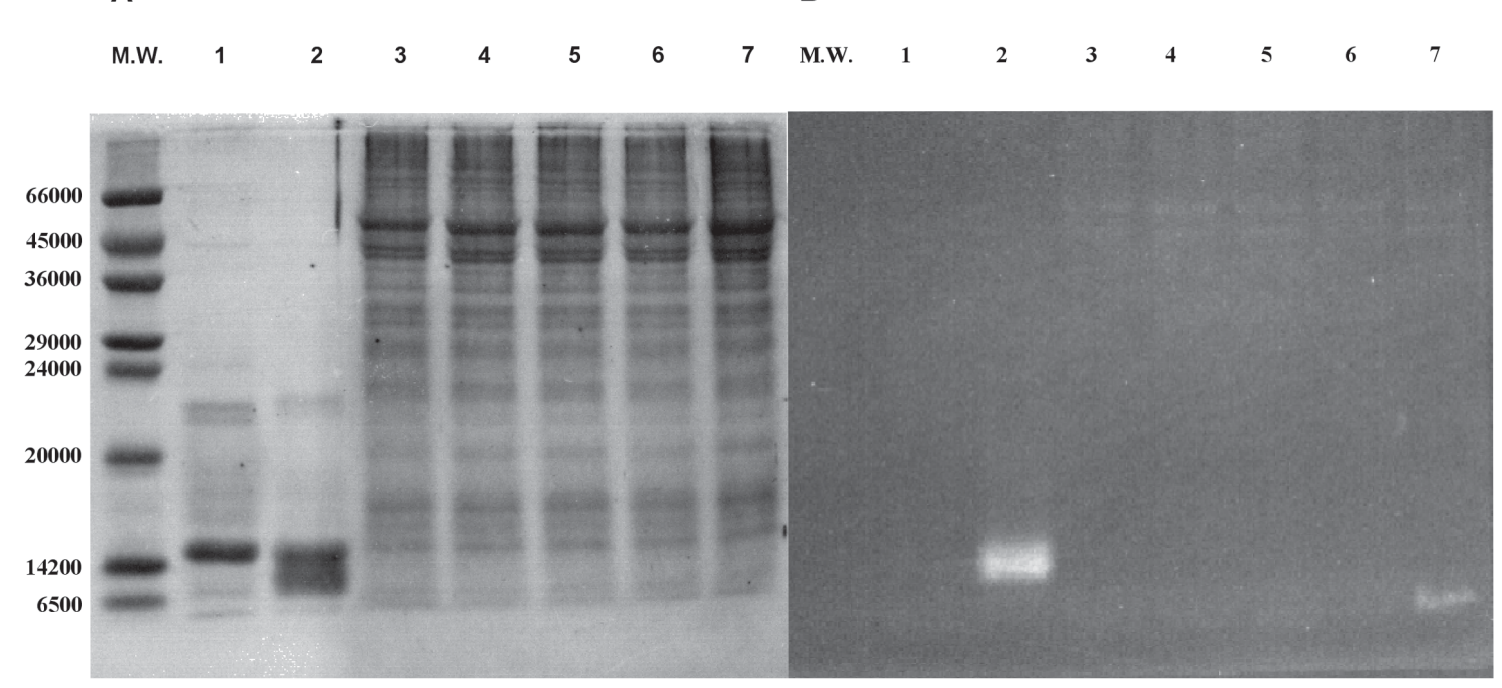

Figure 3. Effect of nifurtimox and benznidazole upon MT-like proteins of Trypanosoma cruzi epimastigotes. $15 \%$ SDS-PAGE electrophoresis. Panel A was stained with Coomasie blue, and Panel B corresponds to UV-transillumination visualization. Line 1 is the standard, underivatized horse kidney metallothionein. Line 2 is the same standard but monobromobimane-derivatized. Lines 3 and 4 correspond to $1.3 \mathrm{mM}$ and $2.6 \mathrm{mM}$ benznidazole treatment, respectively, and lines 5 and 6 correspond to 1.3 and $2.6 \mathrm{mM}$ nifurtimox treatments, respectively (table II). Line 7 is the $T$. cruzi monobromobimane control. Further details in the Materials and Methods section.

and treatment lines in the Coomasie blue gel. Figure $3 \mathrm{~B}$, lines $2 \mathrm{~B}$ and $7 \mathrm{~B}$, show that T. cruzi and horse kidney MT range between 6000 and $14000 \mathrm{KDa}$. Lines 3B to $6 \mathrm{~B}$ show that treatment of the parasites with both nifurtimox and benznidazole produces disappearance of this fluorescent band corresponding to MT. When the two peaks of $T$. cruzi monobromobimane-derivatized MT (Fig. 2) were subjected to SDS-PAGE, no difference in their migration was observed. This indicates that both peaks have a very similar molecular weight. Nevertheless, very low-intensity, small fluorescence bands in the high molecular weight region persist throughout the treatment and control lines.

\section{DISCUSSION}

Metallothionein content in all T. cruzi strains studied was higher during exponential phase of growth, except in the CL-Brener clone (Table I). In the Cl-Brenner clone the MT content did not change significantly between the exponential and the stationary phase. At present we have no explanation for this observation. However, we might speculate that in the CL-Brenner clone the MT protein regulatory processes (synthesis and degradation) do not differ in the two growth phases. Nevertheless, other explanations are possible.

$\mathrm{T}(\mathrm{SH})_{2}$ is the major thiol-containing compound in $T$. cruzi and may play a significant role in the parasite's resistance to nifurtimox and benznidazole (Meister, 1983; Repetto et al., 1996; Maya et al., 1997).

Nifurtimox and benznidazole decrease $\mathrm{T}(\mathrm{SH})_{2}$ and $\mathrm{GSH}$ concentration producing oxidative stress (Repetto et al., 1996; Maya et al., 1997). In this report, both drugs also decreased MT levels (Table II and Fig. 3). The reaction of the nifurtimox or benznidazole's electrophilic metabolites with the MT's thiol groups most probably causes this effect. Such a reaction is similar to the conjugation of the nifurtimox or benznidazole's electrophilic metabolites 
with the thiol groups of $\mathrm{T}(\mathrm{SH})_{2}$ and $\mathrm{GSH}$ (Repetto et al., 1996; Maya et al., 1997).

MTs are inducible by several factors including oxidative and physical stress. The results with $\mathrm{ZnCl}_{2}$ (Table II) indicate that $T$. cruzi MTs are inducible.

The radioactive cadmium method only detects free reduced MTs and consequently, does not detect MTs conjugated with drug metabolites (Table II). Also, MT conjugated with drug metabolites does not react with monobromobimane and thus does not produce fluorescence (Fig. 3). MTs are better radical scavengers than GSH. The rate constant for the reaction of MT with hydroxyl radicals and electrophilic agents is about three hundred times higher than with GSH (Sato and Bremner, 1993).

Nitroheterocyclic agents, such as nifurtimox, produce hydroxyl radicals (Docampo and Moreno, 1984), which may react with thiol groups. In this respect, we may see in Figure 3 that the parasites' treatment with both nifurtimox and benznidazole produces disappearance of the fluorescence bands indicating reaction between MT and drug metabolites. Also, Figure 3 shows that low-intensity fluorescence bands in the high molecular weight range of the gel do not disappear, indicating the presence of proteins with less reactive thiol groups.

In previous reports we showed evidence that correlates $\mathrm{T}(\mathrm{SH})_{2}$ and $\mathrm{GSH}$ concentration with the susceptibility to nifurtimox and benznidazole of several $T$. cruzi strains (Moncada et al., 1989; Repetto et al., 1996; Maya et al., 1997). In this report, we found no direct evidence for the same role of MTs in T. cruzi (tables I and II). Nevertheless, in other organisms, MTs have been shown to have this property (Perego et al., 1998; Lazo et al., 1998; He et al., 2000).

It is probable that MTs and other thiolcontaining compounds, such as ovothiols (Steenkamp and Spies, 1994; Ariyanayagam and Fairlamb, 2001), may contribute to protection of the parasite against oxidative stress.

We conclude that MT-like proteins are present in $T$. cruzi because: i) they can bind cadmium; ii) are heat-stable; iii) they have a molecular weight in the same range as other MTs (Figs. 2 and 3); iv) two possible isoforms elute from the chromatographic columns (as seen in Fig. 2); v) the low O.D. at $280 \mathrm{~nm}$ indicates the absence of aromatic amino acids; and vi) they are induced by zinc (Table II). In addition, these proteins may contribute to the resistance of drugs that act producing free radicals or electrophilic metabolites. As stated in the introduction section of this paper, MTs have been isolated from other protozoa. However, this is the first time that MTs are identified in parasites of medical importance.

\section{ACKNOWLEDGEMENTS}

This research received financial support from Fondecyt-Chile $\mathrm{N}^{\mathrm{o}}$ 1020095. The authors gratefully acknowledge the critical review of this paper by Prof. Bruce Cassels of the Faculty of Science, Universidad de Chile.

\section{REFERENCES}

ARIYANAYAGAM MR, FAIRLAMB AH (2001) Ovothiol and trypanothione as antioxidants in trypanosomatids. Mol Biochem Parasitol 115(2): 189-98

CONTRERAS V, NAVARRO M, DE LIMA A, DURÁN F, ARTEAGA R, FRANCO Y (2002) Early and late molecular and morphologic changes that occur during in vitro transformation of Trypanosoma cruzi metacyclic trypomastigotes to amastigotes. Biol Res 35: $47-58$

COYLE P, PHILCOX JC, CARY LC, ROFE AM (2002) Metallothioneins: the multipurpose protein. Cell Mol Life Sci 59(4): 627-47

DOCAMPO R, MORENO SNJ (1984) Free-radical intermediates in the antiparasitic action of drugs and phagocytic cells. In: PRYOR WA (ed) Free radicals in biology, vol 6, New York: Academic Press, pp: 243-288

DUNN MA, BLALUCK TL, COUSINS RJ (1987) Metallothionein. Proc Soc Exp Biol Med 185: 107-119

EATON D, TOAL B (1982) Evaluation of the Cd/ Hemoglobin Affinity Assay for the Rapid Determination of Metallothionein in Biological Tissues. Tox Appl Pharm 66: 134-142

FAIRLAMB AH, CERAMI A (1985) Identification of a novel thiol-containing co-factor essential for glutathione reductase enzyme activity in trypanosomatids. Mol Biochem Parasitol 14: 187-198

FAIRLAMB AH, HENDERSON GB, BACCHI CJ, CERAMI A (1987) In vivo effects of difluoromethylornithine on trypanothione and polyamine levels in blood forms of Trypanosoma brucei. Mol Biochem Parasitol 24: 185-191

HANADA K, SAWAMURA D, TAMAI K, BABA T, HASHIMOTO I, MURAMATSU T, MIURA N, NAGANUMA A (1998) Novel function of 
metallothionein in photoprotection: metallothionein-null mouse exhibits reduced tolerance against ultraviolet B injury in the skin. J Invest Dermatol 111: 582-585

HE T, WEI D, FABRIS D, FENSELAU C (2000) Intracellular sequestration of antitumor drugs by metallothioneins. Cell Mol Biol 46: 383-392

IRATO P, PICCINNI E, JAMES P, AMMERMANN D (1995) Evidence of a cadmium-thionein and the glycine cleavage system in Oxytricha granulifera. J Eukaryot Microbiol 42: 376-378

JEREMIAS H, KÄGI R (1991) Overview of metallothionein. Methods in Enzymol 205: 613-626

KLAASSEN CD, LIU J, CHOUDHURI S (1999) Metallothionein: an intracellular protein to protect against cadmium toxicity. Annu Rev Pharmacol Toxicol 39: 267-294

KOJIMA Y, BERGER C, VALLEE BL, KÄGI J (1976) Amino-acid sequence of equine renal metallithionein1B. Biochemistry 10: 3413-3417

KOSOWER EM, KOSOWER NS, RADKOWSKY A (1983) Fluorescent thiol labeling and other reactions with bromobimanes; glutathione sulfide. In: LARSSON A, ORRENIUS S, HOLMGREN A, MANNERVIK B (eds) Functions of Glutathione. New York: Raven Press, pp: 243-250

LAZO JS, KUO SM, WOO ES, PITT BR (1998) The protein thiol metallothionein as an antioxidant and protectant against antineoplastic drugs. Chem Biol Interact 111-112: 255-262

MAYA JD, REPETTO Y, AGOSIN M, OJEDA JM, TÉLLEZ R, GAULE C, MORELLO A (1997) Effect of nifurtimox and benznidazole upon the glutathione and trypanothione content in epimastigote, trypomastigote and amastigote forms of Trypanosoma cruzi. Mol Biochem Parasitol 86: 101-106

MAYA J, MORELLO A, REPETTO Y, TÉLLEZ R, RODRÍGUEZ A, NÚÑEZ-VERGARA L, SQUELLA J, BONTÁ M, ROLLO S (1999) Efecto de nitroderivados del megazol, nifurtimox y benznidazol sobre epimastigotes de Trypanosoma cruzi. Biol Res 32: R 157

MAYA J, MORELLO A, REPETTO Y, NÚÑEZVERGARA L, SQUELLA J, BONTÁ M, BOLLO S (2001a) Efecto tóxico de derivados nitroheterocíclicos en el Trypanosoma cruzi. Biol Res 34: 3-4, R-95

MAYA J, MORELLO A, REPETTO Y, RODRÍGUEZ A, PUEBAL P, CABALLERO E, MEDARDE M, NÚÑEZ-
VERGARA L, SQUELLA J, ORTIZ M, FUENTEALBA J, SAN FELICIANO A (2001b) Evaluación del mecanismo de acción de derivados de oxazolo (tiazolo) piridina en Trypanosoma cruzi. Res 34: R53

MAYA JD, BOLLO S, NÚÑEZ-VERGARA LJ, SQUELLA JA, REPETTO Y, PERIE J, CHAUVIÈRE G, MORELLO A (2003) Trypanosoma cruzi: Biol. Res 34: R53. Effect and mode of action of nitroimidazole and nitrofuran derivatives. Biochem Pharmacol 65: 999-1006

MEISTER A (1983) Selective modification of glutathione metabolism. Science 220: 472-477

MONCADA C, REPETTO Y, ALDUNATE J, LETELIER ME, MORELLO A (1989) Role of glutathione in the susceptibility of Trypanosoma cruzi to drugs. Comp Biochem Physiol 94C: 87-91

PEREGO P, ROMANELLI S, CARENINI N, MAGNANI I, LEONE R, BONETTI A, PAOLICCHI A, ZUNINO F (1998) Ovarian cancer cisplatin-resistant cell lines: multiple changes including collateral sensitivity to Taxol Ann Oncol 9(4): 423-30

PICCINNI E, STAUDENMANN W, ALBERGONI V, DE GABRIELI R, JAMES P (1994) Purification and primary structure of metallothioneins induced by cadmium in the protists Tetrahymena pigmentosa and Tetrahymena pyriformis. Eur J Biochem 226(3): 853-859

REPETTO Y, OPAZO E, MAYA JD, AGOSIN M, MORELLO A (1996) Glutathione and trypanothione in several strains of Trypanosoma cruzi. Effect of drugs. Comp Biochem Physiol 115b(2): 281-285

SÁNCHEZ G, CUÉLLAR D, ZULANTAY I, GAJARDO M, GONZÁLEZ-MARTIN G (2002) Cytotoxicity and trypanocidal activity of nifurtimox encapsulated in ethylcyanoacrylate nanoparticles. Biol Res 35: 39-46

SATO M, BREMNER I (1993) Oxygen free radicals and metallothionein. Free Radic Biol Med 14: 325-337

SATO M, KONDOH M (2002) Recent studies on metallothionein: protections against toxicity of heavy metals and oxygen free radicals. Tohoku J Exp Med 196(1): 9-22

STEENKAMP DJ (2002) Trypanosomal antioxidants and emerging aspects of redox regulation in the trypanosomatids. Antioxid Redox Signal 4(1): 105-21

STEENKAMP DJ, SPIES HSC (1994) Identification of a major low molecular mass thiol of the trypanosomatid Crithidia fasciculata as ovothiol A. Eur J Biochem 223: 43-50 